\title{
Forest Land Analysis using Normalized Difference Vegetation Index (NDVI): A Case Study of Bangladesh
}

\author{
Mohammed Shafiul Alam Khan \\ Institute of Information Technology (IIT) \\ University of Dhaka, Dhaka, Bangladesh
}

\author{
Md. Ismail Rahman \\ Institute of Information Technology (IIT) \\ University of Dhaka, Dhaka, Bangladesh
}

\begin{abstract}
It is no longer a secret that Bangladesh is an innocent victim of climate change. Because of climate change, every year the inhabitants of Bangladesh are suffering a lot from the loss of life and property. Various researches, magazines and journals state that Bangladesh is one the most vulnerable nations to the impacts of climate change. Deforestation is the main reason for climate change and global warming. To address the issue, a detailed study of the country's forestation changes and its impact to the prevention of climate change would be helpful. To do so, Landsat 8 dataset images, collected from USGS satellite image dataset, are analyzed, and a model is proposed to detect the changes of forestation between years. The proposed modelhelps to predict the forestation changes in near future and support to take necessary measures to reduce deforestation. Supervised classification and machine learning algorithm are used to implement the model.
\end{abstract}

\section{General Terms}

Image Processing, Machine Learning

\section{Keywords}

Supervised classification, Google Earth Engine, Bangladesh forest land change analysis, NDVI, CART, satellite image dataset

\section{INTRODUCTION}

Global climate change and its impact has become a great concern for Bangladesh. It is no longer a secret that Bangladesh is an innocent victim of climate change. Because of climate change, every year the inhabitants of Bangladesh are suffering a lot from the loss of life and property. In Bangladesh, natural disasters like sea level rise, storms, cyclones, drought, erosion, landslides, flooding and salinization occur more frequently because of the impact of climate change. National Geographic states that Bangladesh is one the most vulnerable nations to the impacts of climate change [1]. The Environmental Justice Foundation report states that, it has been estimated that by 2050 , one in every seven people in Bangladesh will be migrated by climate change and may lose approximately $11 \%$ of its land, affecting an estimated 15 million people living in its low-lying coastal region [2]. The Scientific American published a research on the climate change of Bangladesh and described it as a tragedy [3]. Deforestation is the main reason behind these climate change and global warming.

Now-a-days, many countries are concerned about climate change and its impact. Because of deforestation, climate is changing drastically which is causing natural disasters more frequently and global warming. Therefore, countries are focused on sustainable forestation to save their remaining forest land. To do so, a monitoring system is required which will be able to monitor forestation status and give a statistical result that will help the authority to take decisions to minimize deforestation. If the forestation monitoring system monitors through satellite that will be much cost efficient and easy to implement. In this paper such a system is proposed.

The rest of the paper is structured as follow. Section 2 presents the technical detail to comprehend the work described in this paper, followed by the relevant works in Section 3. The methodology is described briefly in Section 4. The research finding is presented in Section 5. The paper ends with conclusion and future work inSection 6.

\section{BACKGROUND STUDY}

Multi-Spectral Remote Sensing images are very efficient for obtaining and understanding the earth environment $[4,5]$. These images carry essential information and help extracting the features in form of Spectral, Spatial and Temporal about some objects or area, such as vegetation, land cover classification, urban area, agriculture land and water resources without coming into physical contact of these objects $[4,6,7]$. In this work, the multispectral image of Bangladesh is used to detect the forestation changes.The images are collected from Landsat 8 dataset images of USGS satellite image dataset with Google Earth Engine (GEE).

The National Aeronautics and Space Administration (NASA) of USA uses 7-band data for feature extraction, and it is called the Landsat image $[4,8]$. It consists of 9 spectral bands of Operational Land Imager (OLI) and 2 spectral bands of Thermal Infrared Sensor (TIRS) and the result is accomplished using 3 bands named near infrared band, red band and green band. These bands contain specific information which is formulated to get the result. On the basis of wavelength, remote sensing is classified into three types: visible and reflective infrared remote sensing, thermal infrared remote sensing, and microwave remote sensing [4,9]. In this work, Landsat 8 selected bands are formulated with NDVI formula and visualized using different parameters which helps to detect forestation changes throughout the years.

Google Earth Engine provides tools for analyzing the image through different indices. There are various indices for highlighting vegetation bearing areas on a remote sensing scene. NDVI is the most used index in the field of remote sensing. It is an important vegetation index, widely applied in research on global environmental and climatic change [4,10]. NDVI is calculated as a ratio difference between measured canopy reflectance in the red and near infrared bands respectively $[4,11]$. NDVI is often used to monitor vegetable health by researchers. In this paper, using NDVI on satellite images, the researcher detected the changes of forestation and compared between the base year and the present year.

Supervised classification is a process in which a user supervises the classification process [12]. In this study the user specifies the 
pixels that should be associated with each class and then processed through the image processing software to use these training data as references for the classification of all other pixels in the image [12]. The general workflow for Supervised classification is as follow. Firstly,collect training data which have a property that is stored in the known class label.Secondly, instantiate a classifier and set its parameters. Thirdly,train the classifier using the training data. Later,classify the feature collection of images, and finally, estimate classification error with validation data [13]. In this work, the researchers used the Classification and Regression Trees (CART) machine learning algorithm for supervised classification.

Google Earth Engine classifiers include CART, RandomForest, Naïve Bayes and SVM machine learning algorithms. CART is widely known as a decision tree. In supervised classification, the machine learning algorithm CART is the best approach to solve classification and regression problems by continuously splitting data based on a certain parameter [14].

The confusion matrix is a way to evaluate the performance of a classifier. It is an error matrix which is used to assess the thematic accuracy of a land-cover map and summarize the information contained in this error matrix [15]. It is helpful to measure Recall, Precision;specificity, Accuracy and AUCROC Curve. In this work, to justify the accuracy of classification of supervised classification confusion matrix is applied on the result of classification. To determine the accuracy,the summation of True Positive pixels and True Negative pixels are divided by the total no of pixels. After getting satisfactory results from the confusion matrix of training data, the classification of the whole bound pixel of Bangladesh is proceeded. Here, accuracy refers to out of all the classes, how much the classification has predicted correctly.

\section{RELATED WORKS}

Many researchers have focused on minimizing the impact of climate change and implementing sustainable forestation through monitoring and detecting forest land from satellitesimages [16, 18 - 27]. The work presented in this paper is inspired by the research on deforestation area estimation in China [16] and Climate change impacts and adaptation assessment in Bangladesh [17].

In recent years, several researchers had detected and visually analyzed the forest land changes and degradation of several countries with NDVI using the Google earth engine application $[18,19,20]$. Some researchers had assessed the deforestation status in real time by using satellite images and monitored the changes of deforestation [21, 22, 23]. Other researchers proposed a deforestation detection system in near real time [24, 25]. Few researchers focus on satellite image mapping and classification for identifying cropland [26, 27]. Zhang et al. had done forest classification on Hainan Island using timeseries sentinel-1 and landsat- 8 images [28]. Yu et al. work on land cover classification of Bangladesh using Google Earth Engine [29]. Following these researchers, the work described in this paper detects and visually analyzesthe forest land of Bangladesh using NDVI. The authorsvisually represent the forest degradation of the forest land of Bangladesh using Google Earth Engine application.

\section{METHODOLOGY}

To detect the forestation changes throughout the years, at first, a suitable platform, i.e. Google Earth Engine (GEE),is selected to do the simulation. GEE has the facility to use various satellite image dataset and the processing speed of GEE is much faster using Google data center. Also, GEE shows the visual result of the image which is very helpful for the representation of the analysis.

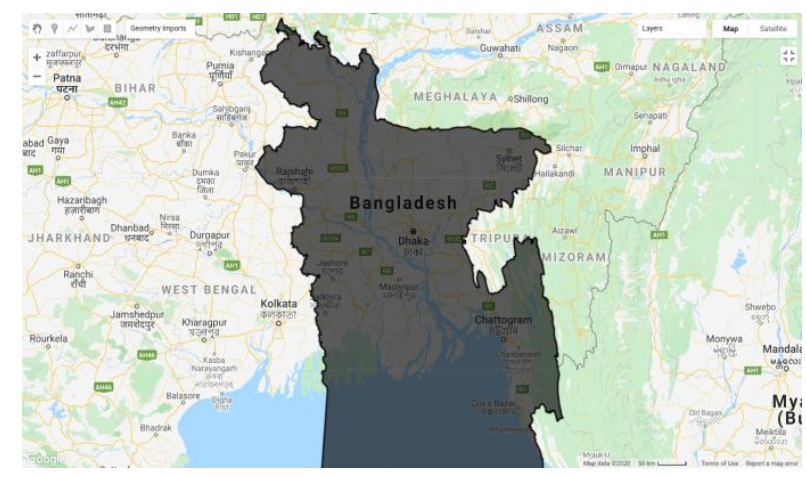

Fig 1: Bangladesh polygon design on GEE

Bangladesh shaped proper border outline polygon is designed using map coordinates. Then, USGS Landsat 8 Collection 1 Tier 1 and Real-Time data TOA Reflectance image dataset is imported in GEE platform and Bangladesh shaped polygon is impressed on imported GEE Landsat 8 images where Bangladesh shaped clipped polygon (See Figure 1) is constructed. Since, Landsat 8 image dataset is the most recent dataset, it is used for the analysis.

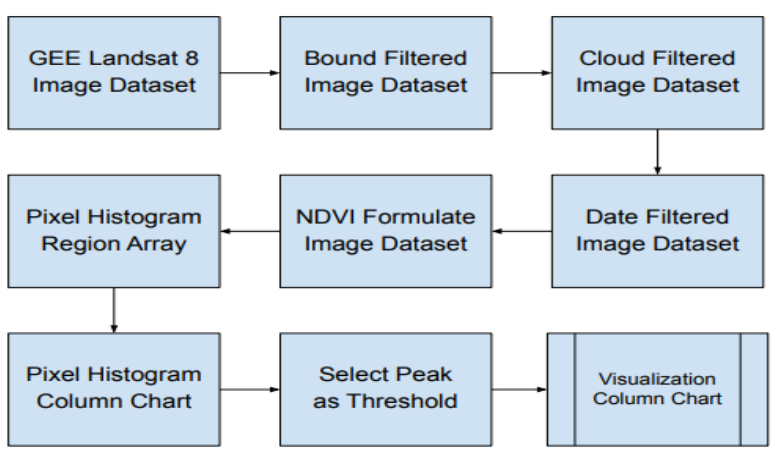

Fig 2: Activity flow diagram of generating NDVI histogram chart

After that, image datasets are bound, cloud and date filtered. As NDVI is the most suitable index for vegetable monitoring, the researcher formulated NDVI on filtered images. The histogram chart is generated from all pixels NDVI values. Since, peak value is the most frequent NDVI value in the whole bound image, peak value is selected as threshold. The activity flow diagram of generating NDVI histogram chart is shown in Figure 2. Histogram chart is shown in Figure 3. In Figure 3, x-axis represents NDVI values and $y$-axis represents number of pixels. Here, the threshold value is 0.523 . This threshold value is the most frequent NDVI value in the whole bound area, and so, it is used to detect forestation.

The threshold from histogram chart is applied to both base year and chosen year bound polygon image dataset (for comparison) which also pursue the process of filtration and formulation as described above. The activity flow diagram of visual representation of forestation in a year is shown in Figure 4. 


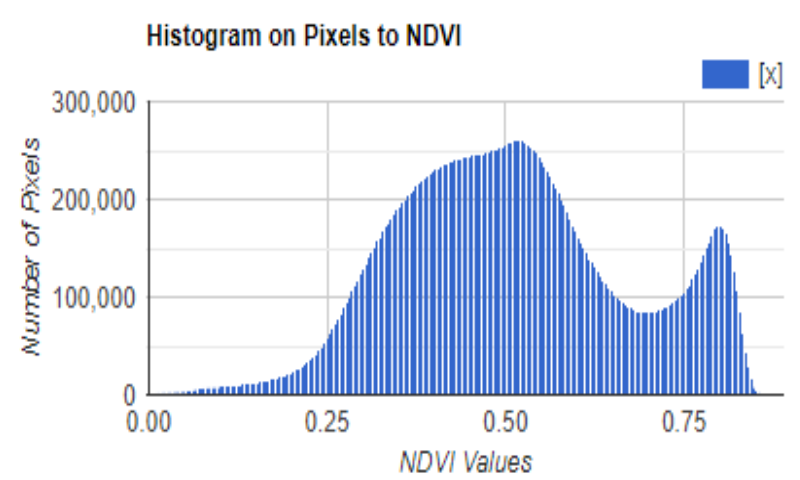

Fig 3: Pixel-NDVI histogram column chart

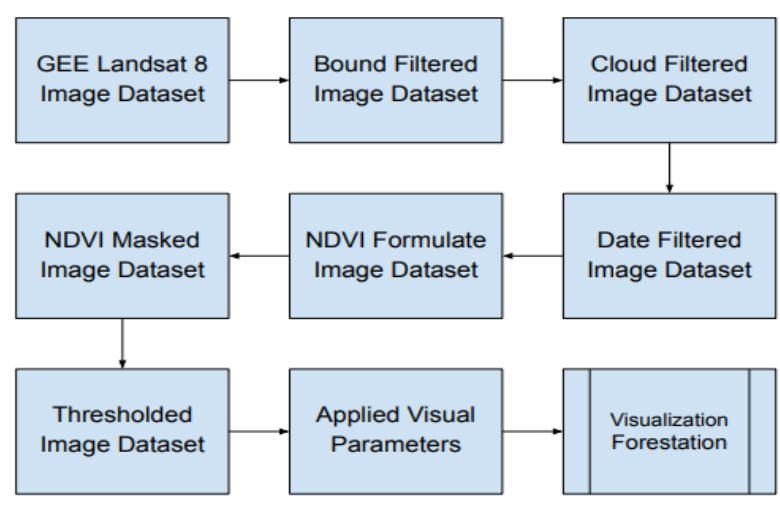

Fig 4: Activity flow diagram of visual representation of forestation

The processed images are then visualized using different parameters to provide a clear concept of changes(see Figure 5). In Figure 5 red color indicates the forest land of base year, blue color indicates the forest land of chosen year, green color indicates the intact forest land, white color indicates the urbanized or barren land and black color indicates the water.

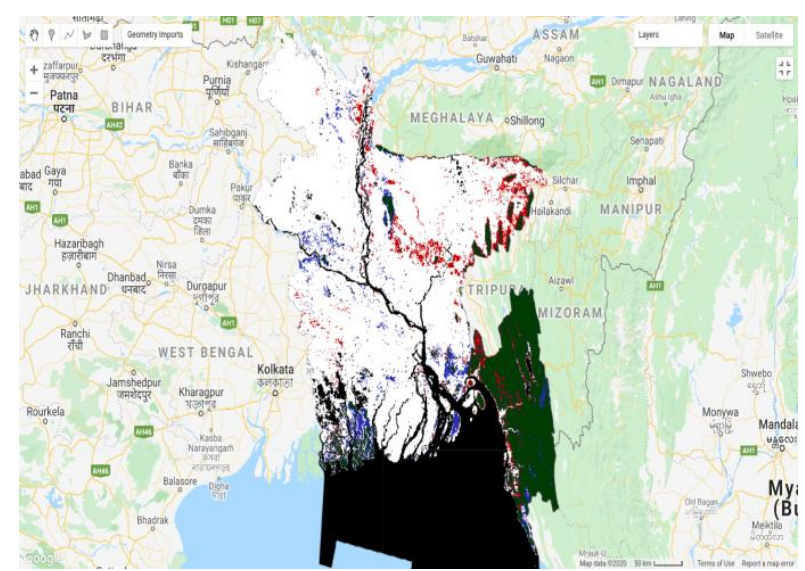

Fig 5: Visual representation of forestation with changes

To detect the intact forest land, both base year and chosen year images are merged using AND operator. Thus,changesof the forest land between years are found.The activity flow diagram to detect the intact forest land is shown in Figure 6.

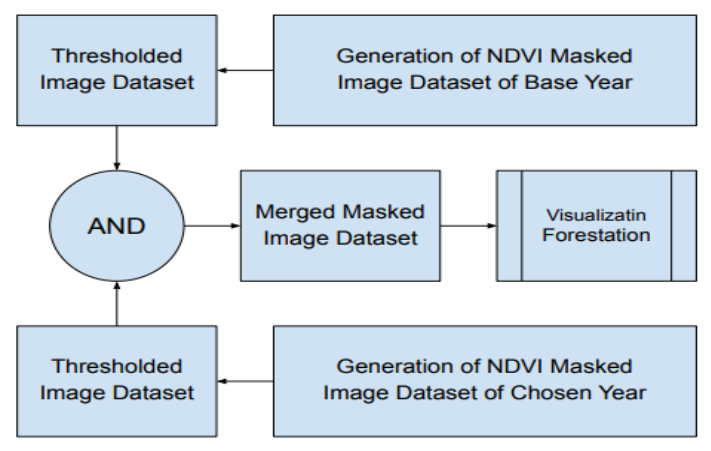

Fig 6: Activity flow diagram to detect the intact forest land

Forest land detection includes all the green trees in Bangladesh which also includes non-forest human planted trees. That's why, to get the accurate calculation of forest land area of Bangladesh,some supervised pixel values are selected as training data. Those data are utilized to train the model using CARTmachine learning model which is also known as decision tree and accuracy is tested using confusion matrix. After perfection of training data, all bounded pixel values are classified using CART and accuracy is tested using confusion matrix. If the accuracy is satisfactory then forest and non-forest area classification is completed.The accuracy of the training data in the proposedmodel is $99.8 \%$. The activity flow diagram of classified intact forest land area calculation is shown in Figure7.

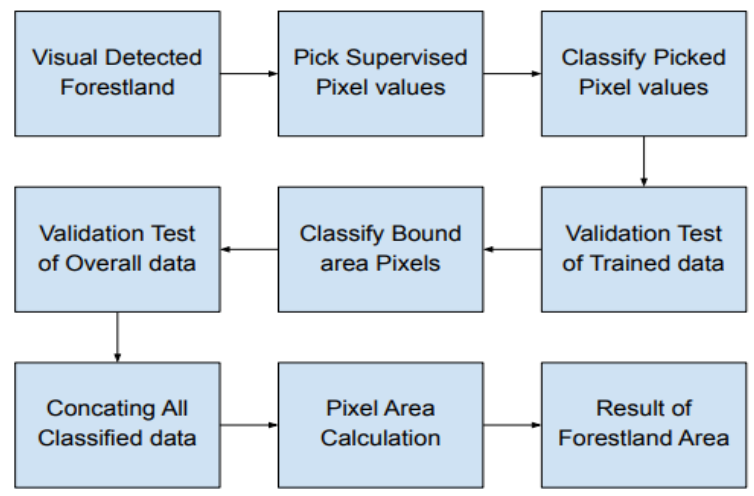

Fig 7: Activity flow diagram of forest land area calculation

To calculate the forest land area, the classified result is concatenated to get the aggregated result and pixel area calculation is done using pixel count method. In calculation pixel area is divided by $1000 * 1000$ to get the result in square kilometers. Using summation of classified values, the total forest land area of Bangladesh is calculated.

\section{RESULT AND DISCUSSION}

Keeping 2016 as a base year, Figure 8 shows the forestation changes from year 2017 to year 2020, where, $x$-axis represents the year and $y$-axis represents area of the forest land in square kilometer. The histogram chart (see Figure 8) is the comparative study of base year 2016 and the chosen year. In the graph, green column bar indicates the intact forest land, blue column bar indicates the gained forest land and red column bar indicates the lost forest land in Bangladesh throughout the years. 


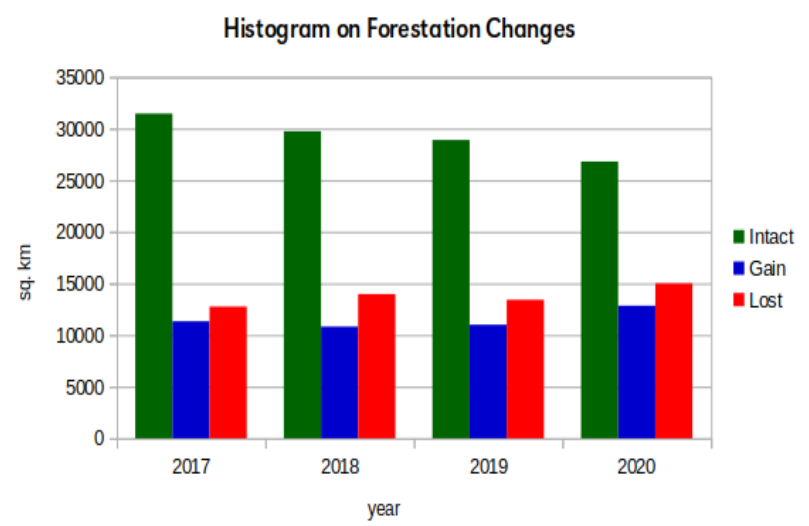

Fig 8: Changes of forest land

The data presented in Figure 8 is generated from the NDVI values of the whole bound of Bangladesh, whichconsidered all the green trees in Bangladeshincluding non-forest human planted trees. Therefore, to get an accurate forest land area of Bangladesh,the supervised classification on the intact forestarea of Bangladesh is used.The forest land area calculation from year 2017 to year 2020 is done using area calculation of classified data and the percentage of forest land area of Bangladesh is calculated accordingly. The result is shown in Table 1.

Table 1: Statistics of forest land area using the proposed

\begin{tabular}{|c|c|c|c|}
\hline Year & $\begin{array}{c}\text { Forest land } \\
\text { area (in sq. } \\
\text { KM) }\end{array}$ & $\begin{array}{c}\text { Percentage of } \\
\text { forest land } \\
\text { area }\end{array}$ & $\begin{array}{c}\text { Percentage of } \\
\text { accuracy }\end{array}$ \\
\hline 2017 & 22,885 & 15.50 & 95.80 \\
\hline 2018 & 22,337 & 15.13 & 95.48 \\
\hline 2019 & 19,174 & 12.99 & 94.8 \\
\hline 2020 & 17,559 & 11.90 & 93.13 \\
\hline
\end{tabular}

From the resultant data, it is clear that the intact forest land of Bangladesh is decreasing each year because of deforestation from various reasons and the loss of forest land is increasing alarmingly. If deforestation continues in such rate, in near future Bangladesh will surely be a great sufferer from global warming. It is also clear that the recovery of forest is not enough to cope with deforestation. Therefore, the trend of total forest land in Bangladesh is downward as shown in Figure 9.

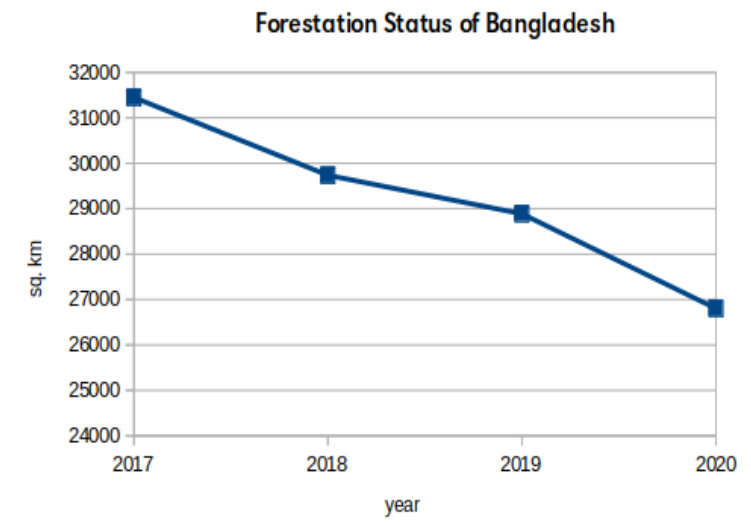

Fig 9: Forestation status of Bangladesh

\section{CONCLUSION AND FUTURE WORK}

In the present world, climate change and global warming have become a great concern for the existence of humanity. If proper resolution is not taken immediately, humanity may face a great threat in future. The future generation may not be able to survive in an adverse environment. So, the only solution is to save the trees, save the forests and save the environment. In this paper, a machine learning model is presented that can detect the forestation changes throughout the years from satellite image collection dataset. These findings could support the decisionmakers to effectively responsein resolving climate issues. In future, using this modelone canalso be able to determine urbanized land, water area, crop land etc.

\section{REFERENCES}

[1] National Geographic magazine of May 2011: https://www.nationalgeographic.com/magazine/2011/05/ban gladesh/ (Accessed June 5, 2021)

[2] Environmental Justice Foundation report: https://ejfoundation.org/reports/climate-displacement-inbangladesh(Accessed June 5, 2021)

[3] Scientific American blog April 2017: https://blogs.scientificamerican.com/guest-blog/theunfolding-tragedy-of-climate-change-inbangladesh(Accessed June 5, 2021)

[4] Meera Gandhi, G. \& Arun, S.Parthiban \& Thummala, Nagaraju \& Christy, A.,"NDVI: Vegetation Change Detection Using Remote Sensing and GIS - A Case Study of Vellore District", Procedia Computer Science. 57. pp. 11991210,2015

[5] Ahmadi H, Nusrath A, "Vegetation change Detection of Neka river in Iran by using remote sensing and GIS", Journal of Geography and Geology, 2 (1), pp. 58-67, 2012

[6] Karaburun A. A. K. Bhandari, "Estimation of C factor for soil erosion modelling using NDVI in Buyukcekmece watershed", Ozean Journal of applied sciences 3, pp. 77-85, 2010

[7] Chouhan R, Rao N,"Vegetation detection in Multi spectral remote sensing images: protective role-analysis of coastal vegetation in 2004 Indian Ocean Tsunami Geo-Information for Disaster Management", Procedia Technology 6, pp. 612621,2012

[8] Hu Y, Ban Y, Zhang X, Liu J, Zhuang. D, "Spatial- temporal pattern of GIMMS NDVI and its dynamics in Mongolian Plateau", In IEEE Proceeding on Earth Observation and Remote Sensing Applications, pp. 1-6, 2008

[9] Merwan Achibeta, Stefan Balevb, Antoine Dutotb, Damien Olivierb, "A Model of Road Network and Buildings Extension Co-Evolution Agent-based Modeling and Simulation of Cities", Procedia Computer Science. 32, pp. $828-833,2014$

[10] A.K. Bhandari, A. Kumar, "Feature Extraction using Normalized Difference Vegetation Index (NDVI): A Case Study of Jabalpur City", Proceedings of Communication, Computing \& Security. Procedia Technology Volume 6, pp. 612-621, 2012

[11] Nageswara PPR, Shobha SV, Ramesh, KS, Somashekhar RK, "Satellite -based assessment of Agricultural drought in Karnataka State", Journal of the Indian Society of Remote Sensing, 33 (3), pp. 429-434, 2005 
[12] Supervised classification:

http://gsp.humboldt.edu/OLM/Courses/GSP_216_Online/lesso n6-1/supervised.html(Accessed January 11, 2021)

[13] Google Earth Engine Supervised Classification:https://developers.google.com/earthengine/guides/classification(Accessed January 15, 2021)

[14] S. Ray, "A Quick Review of Machine Learning Algorithms", International Conference on Machine Learning, Big Data, Cloud and Parallel Computing, Faridabad, India, pp. 35-39, 2019

[15] Stephen V. Stehman, "Selecting and interpreting measures of thematic classification accuracy", Remote Sensing of Environment, Volume 62, Issue 1, pages 77-89, 1997

[16] X. Wang, Y. Zhang, E. Yan, G. Huang, C. Cao and X. Ni, "Deforestation area estimation in China based on Landsat data", IEEE Geoscience and Remote Sensing Symposium, Quebec City, QC, pp. 4254-4256, 2014

[17] Ali, A., "Climate change impacts and adaptation assessment in Bangladesh", Climate Research 12 (1999): 109-116, 1999

[18] R. Jena and B. Pradhan, "A Model to Detect Forest Change Relating to Mining using Google Earth Engine Application in Belitung Island, Indonesia", 6th International Conference on Space Science and Communication (IconSpace), Johor Bahru, Malaysia, 2019, pp. 47-52, 2019

[19] E. Arai, Y. E. Shimabukuro, A. C. Dutra and V. Duarte, "Detection and Analysis of Forest Degradation by Fire Using Landsat/Oli Images in Google Earth Engine," IGARSS 2019 - 2019 IEEE International Geoscience and Remote Sensing Symposium, Yokohama, Japan, 2019, pp. $1649-1652,2019$

[20] X. Zhang, T. Long, G. He and Y. Guo, "Global Forest Cover Mapping using Landsat and Google Earth Engine cloud computing", 2019 8th International Conference on Agro-Geoinformatics (Agro-Geoinformatics), Istanbul, Turkey, 2019, pp. 1-5, 2019

[21] L. O. Anderson, Y. E. Shimabukuro, R. S. Defries and D. Morton, "Assessment of deforestation in near real time over the Brazilian Amazon using multitemporal fraction images derived from Terra MODIS", in IEEE Geoscience and Remote Sensing Letters, vol. 2, no. 3, pp. 315-318, 2005

[22] D. Haboudane and E. M. Bahri, "Deforestation Detection and Monitoring in Cedar Forests of the Moroccan Middle-Atlas Mountains", 2007 IEEE International Geoscience and Remote Sensing Symposium, Barcelona, pp. 4327-4330, 2007

[23] J. Verbesselt, M. Kalomenopoulos, C. Souza and M. Herold, "Near real-time deforestation monitoring in tropical ecosystems using satellite image time series", 2012 IEEE International Geoscience and Remote Sensing Symposium, Munich, pp. 2020-2023, 2012

[24] C. G. Diniz, A. A. de Almeida Souza, D. C. Santos, M. C. Dias, N. C. da Luz, D. R. V. de Moraes, M. Adami, "DETER-B: The New Amazon Near Real-Time Deforestation Detection System", in IEEE Journal of Selected Topics in Applied Earth Observations and Remote Sensing, vol. 8, no. 7, pp. 3619-3628, 2015

[25] E. Menaka, S. S. Kumar and M. Bharathi, "Change detection in deforestation using high resolution satellite image with Haar wavelet transforms", 2013 International Conference on Green High-Performance Computing (ICGHPC), Nagercoil, pp. 1-7, 2013

[26] J. Useya, S. Chen and M. Murefu, "Cropland Mapping and Change Detection: Toward Zimbabwean Cropland Inventory," in IEEE Access, vol. 7, pp. 53603-53620, 2019

[27] J. Song, M. Xing, Y. Ma, L. Wang, K. Luo and X. Quan, "Crop Classification Using Multitemporal Landsat 8 Images," IGARSS 2019 - 2019 IEEE International Geoscience and Remote Sensing Symposium, Yokohama, Japan, pp. 2407-2410, 2019

[28] L. Zhang, X. Wan and B. Sun, "Tropical Natural Forest Classification Using Time-Series Sentinel-1 and Landsat-8 Images in Hainan Island," IGARSS 2019 - 2019 IEEE International Geoscience and Remote Sensing Symposium, Yokohama, Japan, pp. 6732-6735, 2019

[29] Z. Yu, D. Liping,T. Junmei, Z. Chen, L. Li, G. Y. Eugene, M. S. Rahman, G. Juozas, and S. Ziheng, "Land Use and Land Cover Classification for Bangladesh 2005 on Google Earth Engine," 7th International Conference on Agro-GeoInformatics, Hangzhou, pp. 1-5, 2018. 